\title{
Evaluation of Liver Enzymes in End-Stage Renal Disease Patients on the Renal Transplant-Waiting List in North-West of Iran
}

\author{
Samaneh Sabouri (iD ${ }^{1}$, Monavar Afzal Aghaee (iD) ${ }^{1}$, Zahra Lotfi (iD) ${ }^{2,}$, , Habibollah Esmaily (iD) ${ }^{1}$, Maryam \\ Alizadeh (iD ${ }^{1}$ and Hooman Mosannen Mozafari (iD ${ }^{3}$ \\ ${ }^{1}$ Department of Epidemiology and Biostatistics, School of Health, Mashhad University of Medical Sciences, Mashhad, Iran \\ ${ }^{2}$ Kidney Transplantation Complications Research Center, Mashhad University of Medical Sciences, Mashhad, Iran \\ ${ }^{3}$ Gastroenterology \& Hepatology Research Center, Mashhad University of Medical Sciences, Mashhad, Iran \\ "Corresponding author: Kidney Transplantation Complications Research Center, Faculty of Medicine, Mashhad University of Medical Sciences, Mashhad, Iran. Tel: \\ +98-9153167280, Email: lotfiz@mums.ac.ir
}

Received 2020 July 25; Accepted 2020 August 14.

\begin{abstract}
Background: Liver diseases, mainly hepatitis B and C, commonly occur in patients with end-stage renal diseases (ESRD). Alanine and aspartate aminotransferase are important for the diagnosis and monitoring of liver diseases. Several studies demonstrated that patients with chronic kidney disease (CKD) have lower levels of serum aminotransferases than the normal population. The present study was designed to compare these enzymes in different types of dialysis in ESRD patients and the general population in Iran.

Methods: In this cross-sectional study, ESRD patients who were candidates for organ transplants in Montaserieh Hospital in Mashhad (Iran) from 2007 to 2014 were enrolled. The data of 1116 patients were collected by reviewing their medical records. Patients were divided into two groups of hemodialysis $(n=1034)$ and peritoneal dialysis $(n=82)$; their liver enzymes were compared with 510 healthy individuals from the MASHAD study.

Results: There was a significant difference between hemodialysis and peritoneal dialysis patients and the control group regarding the age $(\mathrm{P}<0.0001)$ and gender $(\mathrm{P}=0.005)$.

Conclusions: The reduction in serum aminotransferase levels in ESRD cases compared to the control group suggested that renal failure influences liver enzymes that were mildly increased in peritoneal dialysis versus hemodialysis patients in samples provided before the dialysis session.
\end{abstract}

Keywords: Chronic Kidney Diseases (CKD), Aminotransferase, Hemodialysis, Peritoneal Dialysis

\section{Background}

Liver diseases are common among patients with endstage renal diseases (ESRD), particularly hepatitis B and C. The most important enzymes used to detect/diagnose hepatobiliary disease include aminotransferases, alkaline phosphatase, and gamma-glutamyl transferase (GGT). Aminotransferase tests, including alanine aminotransferase (ALT) and aspartate aminotransferase (AST), have a significant role in the diagnosis and monitoring of liver diseases; as they are present in small concentrations $(<40$ $\mathrm{IU} / \mathrm{L}$ ) in the blood circulation of normal individuals.

Patients with ESRD often have abnormal serum enzymes because of two main reasons: (a) their impaired excretion; and (b) the presence of comorbidities. Among such enzymes, liver enzymes have a crucial role in this respect.

Several studies demonstrated that patients with chronic kidney disease (CKD) have lower serum levels of aminotransferases than the normal population (1-4). Its main etiology has not yet been fully understood; however, two main hypotheses have been suggested: first, the lack of serum Pyridoxine or vitamin B6 (Pyridoxal phosphate is an essential coenzyme for ALT) (5-7); and secondly, the inhibition of serum transaminases activity due to the presence of various inhibitors in the uremic environment (when the ultraviolet method is used by SMA 6/12 auto analyzers, the absorption of the ultraviolet light by uremic toxins results in the false low concentrations of serum transaminases). The decreased level of aminotransferase can also be attributed to the hemodilution caused by the accumulation of water before dialysis and enhanced levels of homocysteine $(8,9)$.

In another study, the increase in AST level following hemodialysis (HD) was attributed to the removal or elimination of inhibitors via dialysis (1). However, this is not

Copyright (c) 2020, Author(s). This is an open-access article distributed under the terms of the Creative Commons Attribution-NonCommercial 4.0 International License (http://creativecommons.org/licenses/by-nc/4.0/) which permits copy and redistribute the material just in noncommercial usages, provided the original work is properly cited. 
the isolated effect of the urea toxin since the addition of urea to the serum of a normal individual does not result in reduced AST activity. Such conditions usually negatively influence the precise paraclinical diagnosis of various comorbidities in CKD patients, mainly due to the lack of data on the serum concentration of such enzymes.

Some researchers have argued that using the current normal range of transaminases, which was originally defined around 25 years ago, some patients suffering from statosis or hepatitis $\mathrm{C}$ infections might be considered as healthy. It's reported that a decrease in the upper limit of normal (ULN) value of liver enzymes is associated with 55 - 76\% increase in the sensitivity of ALT for the diagnosis of different liver diseases, while its specificity decreases from $97 \%$ to $89 \%$ (1). With respect to several studies, the use of the standard reference levels for transaminases does not seem to be highly beneficial in the diagnosis of liver diseases in patients undergoing chronic dialysis. In a study conducted on more than 500 hemodialysis patients, the standard cut off values of aminotransferases were identified as a poor indicator for diagnosing active hepatic disease in patients with hepatitis $C$ who were undergone liver biopsy (10).

On the other hand, since dialysis patients have a low level of basic serum concentration of aminotransferases, physician should pay special attention even to slight increases in normal ranges, particularly toward underlying pathologic conditions. Therefore, several researchers have argued that by considering the lower limit of normal concentration of aminotransferases, the sensitivity of liver function tests in dialysis patients can be increased $(11,12)$. A study has decreased the upper limit for AST and ALT to $24 \mathrm{IU} / \mathrm{L}$ and $17 \mathrm{IU} / \mathrm{L}$, respectively, (from $40 \mathrm{IU} / \mathrm{L}$ ), which increased the AST and ALT sensitivity of identifying hepatitis B-related liver diseases from 27 to $72 \%$ and 18 to $64 \%$, respectively, in peritoneal dialysis (PD) patients. The current recommended values for the upper normal limit are AST $>24$ $\mathrm{IU} / \mathrm{L}$ and ALT $>17 \mathrm{IU} / \mathrm{L}$.

\section{Objectives}

As there are limited data available on the aminotransferase levels in CKD patients undergoing dialysis in comparison to the general population and also on the difference in transaminase levels according to the type of dialysis (HD vs. PD) in the Iranian population; the present study aimed to find a precise response to the above-mentioned questions.

\section{Methods}

In this cross-sectional study, patients with ESRD who were candidates for organ transplants in Montaserieh Hos- pital, Mashhad (Iran) from 2007 to 2014, were enrolled. The data of 1116 patients were collected by reviewing medical records and other hospital resources. The baseline data included patients' condition at admission and before the initiation of dialysis.

Data regarding age, sex, type and duration of dialysis, possible viral disease, and hepatic enzyme (AST and ALT) levels were collected, and their accuracy was examined. All patients with hepatitis B and C were excluded from the study. The remaining patients were divided into two groups of hemodialysis $(\mathrm{n}=1034)$ and peritoneal dialysis $(\mathrm{n}=82)$.

Moreover, to compare the liver enzymes serum level of healthy individuals with ESRD cases undergoing HD and PD, the data of MASHAD study were used. Accordingly, by measuring the GFR level by the CKD-EPI equation, patients with normal kidney function (GFR > 90) were identified. Eventually, using a random sampling technique, 510 cases were selected as the healthy controls.

Data were analyzed by SPSS version 16 . The Chi-square test and independent-sample t-test were used for intergroup comparisons; Statistical significance was considered when P-value $<0.05$.

\subsection{Ethical Issues}

This research was performed following the Declaration of Helsinki principles. Informed written consent was obtained from all participants.

\section{Results}

The present study was conducted on 1116 ESRD patients who were undergoing either HD or PD and were candidates for renal transplantation. 1034 (92.6\%) and 82 (7.7\%) of patients were undergoing hemodialysis and PD, respectively. For hemodialysis patients, samples were collected before the hemodialysis session.

In total, 1116 cases were studied. The mean age of participants was $39.38 \pm 13.49 \mathrm{yrs}$, who $43 \%$ of them were male. There was a meaningful difference between HD and PD cases and patients with normal kidney function regarding the age $(\mathrm{P}<0.0001)$; a meaningful difference was found between these three groups concerning the gender $(\mathrm{P}=$ 0.004); so that the prevalence of receiving peritoneal dialysis was higher among males (Table 1 ).

Furthermore, the etiology of ESRD was also investigated among hemodialysis patients; based on the findings, diabetes, hypertension, and glomerulonephritis were the most common causes of ESRD. Among the peritoneal dialysis patients, hypertension, urinary tract obstruction, and glomerulonephritis were the most frequent causes. Nevertheless, the etiology of ESRD was unclear in $49.3 \%$ and 


\begin{tabular}{lccc}
\hline \multicolumn{1}{l}{ Table 1. Demographic Data of the Studied Cases in Both the Hemodialysis and Peritoneal Dialysis Groups } & & \\
\hline & Hemodialysis & Peritoneal Dialysis & Healthy Controls \\
\hline Pale, No. (\%) & $429(41.5)$ & $48(58.5)$ & $303(59.5)$ \\
Female, No. (\%) & $605(58.5)$ & $34(41.5)$ & $207(40.5)$ \\
Age, mean \pm SD & $39.72 \pm 13.29$ & $44.47 \pm 21.46$ & $40.47 \pm 3.69$ \\
\hline
\end{tabular}

41.3\% of hemodialysis and peritoneal dialysis patients, respectively (Table 2).

Table 2. Etiology of End Stage Renal Disease in the Studied Patients Based on the Type of Dialysis

\begin{tabular}{lcc}
\hline Etiology & Hemodialysis, No. (\%) & $\begin{array}{c}\text { Peritoneal Dialysis, } \\
\text { No. (\%) }\end{array}$ \\
\hline Diabetes & $120(11.6)$ & $6(7.5)$ \\
\hline Hypertension & $105(10.2)$ & $9(11.2)$ \\
\hline Glomerulonephritis & $62(6.0)$ & $7(8.8)$ \\
\hline $\begin{array}{l}\text { Urinary tract } \\
\text { obstruction }\end{array}$ & $57(5.5)$ & $9(11.2)$ \\
\hline Polycystic kidney & $48(4.6)$ & $4(5.0)$ \\
\hline Congenital disease & $30(2.9)$ & $1(1.2)$ \\
\hline
\end{tabular}

\subsection{AST}

The one-way ANOVA was used to compare the mean level of serum transaminases (AST, ALT) of the three groups: HD, PD, and healthy controls. The Dunnett test was used to evaluate which differences were significant.

The mean serum AST level was $15.21 \pm 5.51 \mathrm{IU} / \mathrm{L}$ in the HD group, $17.12 \pm 5.79 \mathrm{IU} / \mathrm{L}$ in the PD group, and $21.76 \pm 7.16 \mathrm{IU} / \mathrm{L}$ in the control group.

The mean serum level of AST and ALT separated by gender is presented in Table 3. A statistically significant difference was found between the mean AST level in the three groups $(\mathrm{P}<0.0001)$. Also, there was a significant difference between the three groups concerning the mean level of enzyme in males and females $(\mathrm{P}<0.0001)$.

For females, the serum level of liver enzymes was higher in healthy controls than those who were undergoing HD and $\mathrm{PD}(\mathrm{P}<0.0001)$. The same difference was observed in the males' group $(\mathrm{P}<0.01)$.

\subsection{ALT}

The mean ALT level in the HD group was $14.5 \pm 5.64 \mathrm{IU} / \mathrm{L}$, while it was $16.07 \pm 6.83 \mathrm{IU} / \mathrm{L}$ for peritoneal dialysis and $16.03 \pm 7.61 \mathrm{IU} / \mathrm{L}$ for healthy controls.

The mean serum ALT level was compared in general and based on the gender in the three groups, and a significant difference was found between the three groups for both genders $(\mathrm{P}<0.0001)$. Moreover, no significant difference was observed between the mean serum ALT level of PD patients and healthy controls $(\mathrm{P}>0.05)$.

However, there was a statistically significant difference between the two groups of HD and healthy controls ( $\mathrm{P}<$ 0.0001), indicating a higher ALT level in healthy controls compared to the two-hemodialysis groups (Table 3).

\section{Discussion}

This study demonstrated that the mean serum transaminase (AST and ALT) level in dialysis patients (either hemodialysis or peritoneal dialyses) was lower than the control group with normal renal function (Table 3). Furthermore, a meaningful difference was found concerning the serum ALT level between the HD group and the controls ( $14.50 \pm 7.29$ vs. $16.03 \pm 7.30)$.

Several studies have reported a lower ALT and AST level in CKD patients compared to those with normal kidney function $(9,11,13,14)$. It has been hypothesized that there is an association between lower serum ALT levels and the progression of renal failure due to a glomerular lesion. Fabrizi et al. (4) reported that patients undergoing HD had lower levels of ATL than patients with chronic kidney disease on conservative treatment (predialysis); which indicates that progression of impaired renal function is associated with decreased serum levels of ALT. Cohen et al. (1976) also reported a 20 - 50\% decrease in the serum concentration of liver enzymes in $10-90 \%$ of dialysis patients. They assumed that serum ALT level may decrease due to an inadequacy in vitamin B6, which is a coenzyme for ALT, uremic toxins, or hemodilution that occurs due to water retention in CKD patients before the HD session (5-7).

Some researchers argued that dialysis methods contributes to changes in transaminases levels (8). In this study, the mean serum levels of transaminases among the PD group were higher than the HD group (Table 3$)$. In the current study, all samples were collected before dialysis.

The findings of the present study are consistent with the study by Ramos et al. (2011), who studied 20 CAPD and 40 HD patients and concluded that the serum transaminases levels were lower in the CAPD group compared to the HD group before treatment; after hemodialysis, HD pa- 


\begin{tabular}{|c|c|c|c|c|}
\hline & Hemodialysis & Peritoneal Dialysis & Healthy Controls & P-Value \\
\hline \multicolumn{5}{|l|}{ AST } \\
\hline Male & $14.78 \pm 5.45$ & $17.44 \pm 6.50$ & $22.42 \pm 7.02$ & $<0.0001$ \\
\hline Female & $15.79 \pm 5.51$ & $16.91 \pm 5.33$ & $21.32 \pm 7.08$ & $<0.0001$ \\
\hline Total & $15.21 \pm 5.51$ & $17.12 \pm 5.79$ & $21.76 \pm 7.16$ & $<0.0001$ \\
\hline \multicolumn{5}{|l|}{ ALT } \\
\hline Male & $14.83 \pm 5.43$ & $17.21 \pm 7.00$ & $17.38 \pm 8.39$ & $<0.0001$ \\
\hline Female & $14.00 \pm 5.43$ & $15.11 \pm 7.67$ & $15.38 \pm 6.39$ & 0.005 \\
\hline Total & $14.5 .61 \pm 5.64$ & $16.07 \pm 6.83$ & $16.03 \pm 7.61$ & 0.0001 \\
\hline
\end{tabular}

tients had a slightly higher level of serum transaminases (8).

These results indicate that hemodilution may contribute to the reduction of transaminases in hemodialysis patients before treatment. In addition, another recent study reported that hematocrit and ALT levels were increased significantly after hemodialysis, possibly due to loss of excessive accumulated water in HD patients after dialysis, while the accumulation of fluid rarely occurs in PD patients (15). In contrast, Hang et al., in a study that has compared 90 PD patients with healthy controls, concluded that the dialysis method had no role in decreasing the concentration of serum transaminases (16). In this study, despite the higher ALT enzyme level in the control group, the difference between the CAPD and the control group was statistically insignificant.

As mentioned in the literature, the findings of the present study proved that CAPD patients have a lower level of water retention than HD patients; the results were almost similar to the healthy control group. Other studies have reported a strong association between ALT and abdominal adiposity (17). Two studies with large sample sizes have suggested that the cutoff value should be defined by considering both gender and the body mass index $(15,18)$. In accordance with the previous reports that have highlighted the importance of gender in the transaminases concentration (19), in this study also we considered this factor; in total, 639 males and 477 females were investigated.

According to the findings of Mujeeb et al. (2014) and Noha et al. (2016) $(19,20)$, that investigated both males and females, transaminase levels were significantly lower when comparing each dialysis (CAPD-HD) group with the control group $(\mathrm{P}<0.0001)$. As found by the present study, the AST level was significantly higher in the control group than the dialysis groups $(\mathrm{P}=0.0001)$. Moreover, the mean AST level was significantly lower in the CKD patients undergoing dialysis, regardless of the dialysis type, compared to the healthy controls for both genders $(\mathrm{P}<0.0001)$. Although, regardless of the gender, the ALT level was significantly lower in the two dialysis groups compared to the control group $(\mathrm{P}<0.0001)$. Various factors may contribute to this finding, including prescribed drugs, infections, mainly occult hepatitis B and C, and BMI. Further studies are recommended to better clarify the etiology behind such differences.

In the present study, the etiology of ESRD was also investigated; diabetes, hypertension, and polycystic kidney disease were identified as the most common causes. In peritoneal dialysis patients, hypertension, urinary tract obstruction, and glomerulonephritis were the most frequent causes in comparison to others.

The current study had limitations, including extracting patients' information from medical records, using a threshold of $40 \mathrm{IU} / \mathrm{L}$ as the normal transaminase level, and not excluding those with a higher value, not considering unidentified occult hepatitis, the dialysis systems, and control of related complications such as hypertension and high number of diabetic patients. Moreover, since patients were discharged, post hemodialysis tests could not be performed.

\subsection{Conclusions}

A reduction in serum aminotransferase levels in CKD patients who were on dialysis therapy was noticed in this study, suggesting that renal failure influences the liver enzymes. However, further studies are necessary to clarify the reason for hypoaminotransferasemia in CKD patients. Also, the serum aminotransferase levels were slightly increased in the CKD patients who were on PD compared to $\mathrm{HD}$, when the samples were provided before the HD session.

\subsection{Limitations}

The current study had limitations, including extracting patients' information from medical records, using a 
threshold of $40 \mathrm{IU} / \mathrm{L}$ as the normal transaminase level, and not excluding those with a higher value, not considering unidentified occult hepatitis, the dialysis systems, and control of related complications such as hypertension and high number of diabetic patients. Moreover, since patients were discharged, post hemodialysis tests could not be performed.

\section{Acknowledgments}

The authors would like to thank Dr. T. Moghiman for English editing of the paper and the Research Council of Mashhad University of Medical Sciences for supporting the study financially.

\section{Footnotes}

Authors' Contribution: Study concept and design: M. A; acquisition of data: $S$. S; analysis and interpretation of data: M. A., S. S; drafting of the manuscript: Z. L., S. S; critical revision of the manuscript for important intellectual content: H. M. M., M. A., M. A; statistical analysis: M. A., S. S; administrative, technical, and material support: Z. L., M. A; study supervision: H. M. M., Z. L.

Conflict of Interests: The authors declare no conflict of interest.

Ethical Approval: All procedures performed were following the ethical standards of the Ethics Committee of Mashhad University of Medical Sciences (IRB approval number: 931534) and with the 1964 Helsinki Declaration and its later amendments or comparable ethical standards. IR.MUMS.MEDICAL.REC.1394.613

Funding/Support: Research Council of Mashhad University of Medical Sciences is supporting the study financially.

\section{References}

1. Cohen GA, Goffinet JA, Donabedian RK, Conn HO. Observations on decreased serum glutamic oxalacetic transaminase (SGOT) activity in azotemic patients. Ann Intern Med. 1976;84(3):275-80. doi: 10.7326/0003-4819-84-3-275. [PubMed:1259262].

2. Nanji AA. Decreased activity of commonly measured serum enzymes: causes and clinical significance. Am J Med Technol. 1983;49(4):241-5. [PubMed: 6189394].

3. Guh JY, Lai YH, Yang CY, Chen SC, Chuang WL, Hsu TC, et al. Impact of decreased serum transaminase levels on the evaluation of viral hepatitis in hemodialysis patients. Nephron. 1995;69(4):459-65. doi: 10.1159/000188520. [PubMed: 7777113].

4. Fabrizi F, Lunghi G, Finazzi S, Colucci P, Pagano A, Ponticelli C, et al. Decreased serum aminotransferase activity in patients with chronic renal failure: Impact on the detection of viral hepatitis. Am J Kidney Dis. 2001;38(5):1009-15. doi:10.1053/ajkd.2001.28590.
5. Wolf PL, Williams D, Coplon N, Coulson AS. Low aspartate transaminase activity in serum of patients undergoing chronic hemodialysis. Clin Chem. 1972;18(6):567-8. [PubMed: 5026769].

6. Hamfelt A. The effect of pyridoxal phosphate on the aminotransferase assay in blood. Scand J Clin Lab Invest Suppl. 1966;18:Suppl 92:181-8. [PubMed: 5958519].

7. Rej R, Fasce CJ, Vanderlinde RE. Increased aspartate aminotransferase activity of serum after in vitro supplementation with pyridoxal phosphate. Clin Chem. 1973;19(1):92-8. [PubMed: 4683373].

8. Liberato IR, Lopes EP, Cavalcante MA, Pinto TC, Moura IF, Loureiro Junior L. Liver enzymes in patients with chronic kidney disease undergoing peritoneal dialysis and hemodialysis. Clinics (Sao Paulo). 2012;67(2):131-4. doi: 10.6061/clinics/2012(02)07. [PubMed: 22358237]. [PubMed Central: PMC3275117].

9. Lopes EP, Sette LH, Sette JB, Luna CF, Andrade AM, Moraes M, et al. Serum alanine aminotransferase levels, hematocrit rate and body weight correlations before and after hemodialysis session. Clinics (Sao Paulo). 2009;64(10):941-5. doi: 10.1590/S180759322009001000002. [PubMed: 19841699]. [PubMed Central: PMC2763067].

10. Fabrizi F, Lunghi G, Andrulli S, Pagliari B, Mangano S, Faranna P, et al. Influence of hepatitis $C$ virus $(\mathrm{HCV})$ viraemia upon serum aminotransferase activity in chronic dialysis patients. Nephrol Dial Transplant. 1997;12(7):1394-8. doi: 10.1093/ndt/12.7.1394. [PubMed: 9249775].

11. Hung KY, Lee KC, Yen CJ, Wu KD, Tsai TJ, Chen WY. Revised cutoff values of serum aminotransferase in detecting viral hepatitis among CAPD patients: experience from Taiwan, an endemic area for hepatitis B. Nephrol Dial Transplant. 1997;12(1):180-3. doi: 10.1093/ndt/12.1.180. [PubMed: 9157333].

12. Espinosa M, Martin-Malo A, Alvarez de Lara MA, Soriano S, Aljama P. High ALT levels predict viremia in anti-HCV-positive HD patients if a modified normal range of ALT is applied. Clin Nephrol. 2000;54(2):1516. [PubMed: 10968693].

13. Yuki N, Ishida $\mathrm{H}$, Inoue $\mathrm{T}$, Tabata $\mathrm{T}$, Matsushita $\mathrm{Y}$, Kishimoto $\mathrm{H}$, et al. Reappraisal of biochemical hepatitis C activity in hemodialysis patients. J Clin Gastroenterol. 2000;30(2):187-94. doi: 10.1097/00004836200003000-00012. [PubMed: 10730925].

14. Cotler SJ, Diaz G, Gundlapalli S, Jakate S, Chawla A, Mital D, et al. Characteristics of hepatitis $C$ in renal transplant candidates. J Clin Gastroenterol. 2002;35(2):191-5. doi: 10.1097/00004836-20020800000013. [PubMed: 12172367].

15. Prati D, Taioli E, Zanella A, Della Torre E, Butelli S, Del Vecchio E, et al. Updated definitions of healthy ranges for serum alanine aminotransferase levels. Ann Intern Med. 2002;137(1):1-10. doi: 10.7326/0003-4819137-1-200207020-00006. [PubMed:12093239].

16. Crawford DR, Reyna RS, Weiner MW. Effects of in vivo and in vitro dialysis on plasma transaminase activity. Nephron. 1978;22(4-6):41822. doi: 10.1159/000181484. [PubMed: 740106].

17. Ruhl CE, Everhart JE. Trunk fat is associated with increased serum levels of alanine aminotransferase in the United States. Gastroenterology. 2010;138(4):1346-56. 1356 e1-3. doi: 10.1053/j.gastro.2009.12.053. [PubMed: 20060831]. [PubMed Central: PMC2847039].

18. Piton A, Poynard T, Imbert-Bismut F, Khalil L, Delattre J, Pelissier E, et al. Factors associated with serum alanine transaminase activity in healthy subjects: consequences for the definition of normal values, for selection of blood donors, and for patients with chronic hepatitis C. MULTIVIRC Group. Hepatology. 1998;27(5):1213-9. doi: 10.1002/hep.510270505. [PubMed: 9581673].

19. Shittu MO, Adelakun A, Eegunjobi A, Idowu O, Shittu BT. Analysis of Aminotransferases in Predialysis Chronic Kidney Disease Patients. IOSR J Dent Med Sci. 2014;13(4):87-9. doi: 10.9790/0853-13468789.

20. Babekr AAS. The Effect of Hemodialysis on Alanine Transaminase And Aspartate transaminase(ALTEAST) levels in Patients with Renal Failure(thesis). Sudan, North africa: Sudan University of Science \& Technology; 2015. 